\title{
MÁS ALLÁ DEL "PARADIGMA DE LA MEMORIA"1: LA AUTOFICCIÓN EN LA RECIENTE PRODUCCIÓN POSDICTATORIAL ARGENTINA. EL CASO DE 76 (FÉLIX BRUZZONE)
}

\author{
Ilse Logie \\ Universiteit Gent
}

LA PRODUCCIÓN DE LOS "HIJOS": UN TíPICO CASO DE PACTO DE LECTURA MIXTO

Desde principios del siglo XxI, han surgido en la Argentina narrativas autobiográficas sobre la última dictadura, escritas por la generación de los "hijos", que ya van configurando un corpus sustancial de relatos ${ }^{3}$. Como ejemplos representativos de esta producción, cabe mencionar Los topos de Félix Bruzzone (2008), La casa de los conejos de Laura Alcoba (2008), Soy un bravo piloto de la nueva China de Ernesto Semán (2011), Diario de una princesa montonera de Mariana Eva Pérez (2012) o Pequeños combatientes de Raquel Robles (2013). Temáticamente, estas obras tienen en común el hecho de elaborar los recuerdos de las personas que no protagonizaron los acontecimientos traumáticos de la dictadura, pero que sí vivieron sus consecuencias, al ser hijos de padres desapa-

\footnotetext{
${ }^{1}$ El término es de Véronica Garibotto (2008), ver infra.

2 Desde mediados de los años 90, los hijos de desaparecidos se instalan como un nuevo actor tanto en el escenario social argentino como en el artístico. Obtienen sobre todo visibilidad en el espacio público, donde, agrupados en organizaciones como H.I.J.O.S., aparecen vinculados al reclamo de justicia. Para un acercamiento a la producción cultural de estos hijos, véanse el número especial de Journal of Romance Studies y el libro de Ana Ros mencionados en la bibliografía.

${ }^{3}$ Este corpus de textos puede ser considerado un subcorpus de lo que Elsa Drucaroff llama en su estudio Los prisioneros de la torre (2011) la NNA (Nueva Novela Argentina), que consiste principalmente en un conjunto de escritores nacidos entre 1971 y 1989.
} 
recidos por el terrorismo de Estado o de militantes que estuvieron presos, aunque conviene matizar que, en este contexto, el término "hijo" no sólo se refiere a los vínculos parentales, sino también a todos los hijos simbólicos cuya infancia o adolescencia estuvo marcada por la experiencia dictatorial.

Sin embargo, lo que hace innovador y relevante a este corpus desde el punto de vista de la autoficción es el replanteamiento epistemológico al que parece haber llevado la perspectiva transgeneracional, replanteamiento que refleja hasta qué punto se transformaron en los años 90 del siglo anterior las condiciones para narrar el pasado histórico ${ }^{4}$. El cambio de paradigma al que asistimos se manifiesta en diferentes dimensiones de las obras. En lo concerniente al empleo del tiempo, la necesidad de considerar lo ocurrido desde el presente da pie a una complejización de las relaciones entre pasado y presente, y a una conciencia de que la memoria se basa en una reconstrucción siempre precaria, por lo que se impone una dislocación de la cronología del relato. Asimismo, llama la atención la postura enunciativa inédita que se adopta en estas narraciones. Frente a la impresión de transparencia e inmediatez que buscó transmitir la mayoría de las víctimas directas del terror ${ }^{5}$, los autores más jóvenes experimentan con dispositivos de distanciamiento como la mirada infantil, el humor negro o la ironía. Para apartarse tanto de los discursos institucionalizados sobre la memoria como de la tradición discursiva de la denuncia, amplían el tema de la desaparición de personas a modalidades alternativas de representación, tales como la comedia y la fantasía, al tiempo que introducen componentes de ficción en el formato del testimonio empleado antes para indicar que, incluso si la base referencial del relato es completamente real, el autor ha imaginado o novelado unos cuantos elementos. Otra diferencia con respecto a la producción anterior es que, sobre una retórica ideologizada, en los textos más recientes prevalece un discurso anclado en lo íntimo. Por último, en la producción de los hijos hay que destacar el empleo intensivo del comentario metadiscursivo, un rasgo que observamos en la tendencia a registrar el proceso de construcción del relato en el que se trata de reflejar la realidad.

Hace falta precisar que no se trata de un fenómeno aislado y que este discurso distinto, esta ruptura respecto a la forma convencional de hablar sobre la memoria, ha surgido por primera vez en el cine, más precisamente en el fenómeno del "documental subjetivo" (Nichols 1991), con Los rubios (2003) de Albertina Carri como trabajo pionero, por lo que las novelas que nos ocupan cobran mayor sentido cuando se las sitúa en una constelación artística más amplia,

\footnotetext{
4 Dicho replanteamiento hace que ya no alcance la distinción entre escrituras metafóricas y metonímicas de la memoria hecha por Idelber Avelar en su influyente estudio Alegorías de la derrota. Garibotto califica de "paradigma de la memoria" este marco conceptual, que funciona como "un paradigma que gira en torno a [...] la memoria, el duelo, el fracaso, la desestabilización del presente mediante la captura de las ruinas del pasado y a la canonización de dos tipos específicos de narración, la alegoría y el testimonio: el paradigma, en suma, que confluye en el texto de Avelar" (Garibotto 2008: 27-28).

${ }^{5}$ Cabe puntualizar que desde el inicio también se dieron manifestaciones literarias no realistas sino metaficcionales sobre la dictadura: es la modalidad "metonímica" que privilegia Avelar (2000) en sus análisis (un ejemplo serían los textos de Ricardo Piglia).
} 
y aún en pleno desarrollo, de películas, obras de teatro (Mi vida después de Lola Arias), proyectos fotográficos como el de Lucila Quieto, etc. Aunque estas obras forman un continuo, sería erróneo considerarlas un bloque homogéneo, ya que, si todos sus autores expresan el deseo de superar la distancia insalvable que los separa de los seres queridos, difiere considerablemente el grado de problematización que expresan con respecto a la posibilidad de recuperar la memoria y de reconstruir la propia identidad.

En su ya clásico estudio Le pacte autobiographique (1975), el teórico francés Philippe Lejeune basa su definición de la autobiografía en el funcionamiento pragmático de la misma, poniéndola en relación con el nombre propio. Según Lejeune, sólo puede haber autobiografía cuando el productor de una obra promete decir la verdad y propone a su receptor un tipo de contrato ("pacto") que afirma la identidad entre el autor, cuyo nombre aparece en la portada, y el narrador y protagonista, que se evocan en el interior del texto. Sin embargo, como explica Philippe Gasparini, el surgimiento de una tercera configuración pragmática, en lo que él llama el "archigénero autobiográfico", rompe esta "lógica binaria tranquilizadora" (Gasparini 2012: 179) que oponía un pacto autobiográfico a un pacto ficcional, dando paso a un contrato mixto que combina la homonimia entre autor, narrador y personaje con una estrategia de hibridez que subvierte la distinción entre autobiografía y novela autobiográfica: la autoficción.

Ahora bien, en muchos de los relatos de los hijos se observa semejante conjunción de dos pactos de lectura aparentemente antitéticos y, por tanto, supuestamente incompatibles. En estas representaciones autobiográficas de la posdictadura, el pacto novelesco, de índole ficcional, contamina el pacto referencial y biográfico, en el que resuenan, como se verá a continuación, fuertes ecos del testimonio y, en menor medida, de la autobiografía. Esta característica hace que les sea aplicable la definición comúnmente aceptada de la autoficción, en la que el elemento constitutivo es la ambigüedad del pacto (Alberca 2007) o la subversión de los contratos habituales de lectura. La hipótesis de trabajo que subyace en el presente artículo y que está basada en una serie de ejemplos que proceden del corpus de los hijos será, por tanto, que la originalidad de estos relatos se comprende mejor al leerlos desde la malla teórica propia de la noción de autoficción.

A pesar de las divergencias, la mayoría de los críticos coinciden en que la autoficción abarca obras en las que el autor se incluye con todas sus particularidades identitarias (como sucede en la autobiografía clásica), al tiempo que manifiesta una evidente determinación de novelizar su vida (como sucede en la novela autobiográfica canónica). Reconocen también que admitir la posibilidad de un pacto de lectura contradictorio, simultáneamente autobiográfico y novelesco, ha representado una salida a la creciente dificultad de acceder a una verdad objetiva en una época de ausencia de los grandes relatos y construcciones épicas del pasado, lo que permite restablecer la confianza en el discurso autobiográfico. A fin de cuentas, lo que Gasparini prefiere denominar "autonarración" no es sólo una categoría literaria, sino también "un síntoma, un producto y el reflejo de una época" (Gasparini 2012: 204). 
En su recorrido por las principales reflexiones teóricas acerca de la autoficción, Ana Casas (2012) llega a la conclusión de que la etiqueta es lábil, ya que agrupa textos de muy diversa índole, "que tienen en común la presencia del autor proyectado ficcionalmente en la obra (ya sea como personaje de la diégesis, protagonista o no, o como figura de la ficción que irrumpe en la historia a través de la metalepsis o la mise en abyme), así como la conjunción de elementos factuales y ficcionales refrendados por el paratexto" (Casas 2012: 11). Si bien tal heterogeneidad puede producir incomodidad teórica, permite por otra parte que la autoficción pueda operar como una herramienta de innovación que se adapta a las necesidades de un tipo de discurso determinado. Así, en los relatos de los hijos, la autoficción parece ser el único modo posible de plasmar narrativamente las ambigüedades, contradicciones y recovecos tanto de una memoria indirecta y fluctuante como de una identidad quebrada.

Este hecho no debe extrañar, y más bien se relaciona orgánicamente con la historia de la categoría de la autoficción. Interrogándose sobre el éxito espectacular de la noción y sus condiciones de surgimiento en la Francia de finales del siglo XX, Gasparini ha atribuido la cristalización de la autoficción a la convergencia inesperada de tres categorías literarias distintas, identificando una como "el testimonio identitario principalmente judío, feminista y homosexual" (Gasparini 2012: 200). Menciona explícitamente la resonancia universal que cobraron, en los años 70 del siglo $x x$, los relatos autobiográficos de los supervivientes de los campos de concentración nazis como factor que contribuyó a la manifestación de la modalidad autoficcional. En su opinión, las experiencias límite que se creían irrepresentables, el dolor de la supervivencia y la persistencia de las pesadillas potenciaron la búsqueda de formas literarias nuevas para transformar los códigos obsoletos de la escritura autobiográfica y mostrar la insuficiencia del lenguaje convencional (Gasparini 2012: 203). Los textos escritos ahora en la Argentina conectan con este antecedente: en ellos, la autoficción también funciona como un poderoso instrumento de investigación de la propia identidad.

Y las afinidades con las ideas propuestas por Gasparini en torno a la autoficción no se terminan aquí, sino que se prolongan en el plano del contenido. El caso es que este teórico refuta como un error de perspectiva la idea de que en la autoficción contemporánea predominaría la representación exhibicionista de la sexualidad. A su modo de ver, la escritura del yo contemporánea se caracterizaría mucho más por "los temas relativos a la filiación, la memoria colectiva y el duelo" (Gasparini 2012: 187), y parece ser la forma idónea para asumir experiencias dolorosas, paradójicas y fragmentarias.

En este campo semántico es donde se inscriben los relatos autobiográficos argentinos de los hijos, para quienes el recurrir a cierto grado de invención corresponde seguramente a una voluntad expresa de deconstruir la supuesta sinceridad de los discursos anteriores y de conjurar algunas manifestaciones ya caducas de la memoria colectiva, pero aún más a una urgente necesidad biográfica: la de sustituir mediante la ficción a figuras ausentes tan fundamentales como son los padres. En este sentido, el recurso a la ficción es muchas veces el único medio que tienen a su disposición para explorar el enigma que rodea los orígenes familiares y para reconstruir la experiencia de la pérdida. 
Para ilustrar en qué reside la especificidad del corpus en cuestión y cuál es la pertinencia de los mecanismos ficticios de los que se echa mano, me centraré en un libro de cuentos de uno de sus representantes: 76, de Félix Bruzzone, y, más en particular, en el relato "Otras fotos de mamá". 76 es un libro que puede calificarse de autoficcional en su vertiente "biográfica"6, según la clasificación de Vincent Colonna (Casas 2012), ya que se recorta en un horizonte marcadamente autobiográfico, pero construyéndose con los procedimientos de la novela.

\section{¿INCOMPATIBILIDAD DE LOS PACTOS DE LECTURA?}

Como muchos de los textos del corpus abordan el pasado violento a través de la evocación de episodios biográficos, a primera vista parece darse en ellos un regreso al testimonio, formato al que solía ir ligada la primera persona de las víctimas de la última dictadura. En la literatura de la democracia, la figura del testimonio fue crucial tanto para la sociedad (a través de la constitución en 1984 del Nunca Más, el informe de la CONADEP, y en el juicio a las Juntas) como, desde temprano, en la producción literaria (dos ejemplos representativos serían Preso sin nombre, celda sin número del periodista Jacobo Timerman, de 1982, y The Little School, de Alicia Partnoy, escrito en castellano pero publicado en inglés en 1986 desde los EE.UU). Como es sabido, el antecedente más clásico de este género surge en los años 60-70 en América Latina, convirtiéndose rápidamente en una tradición alternativa y contracanónica de todo el subcontinente. Pese a que se trata de un conjunto muy variado de textos, se les ha destacado como rasgos emblemáticos del testimonio, sobre todo desde la academia estadounidense con teóricos como Beverley (1987), por su aspiración a la veracidad y el hecho de dar voz a una experiencia colectiva de represión, que quedó brutalmente silenciada. Contrariamente a lo que ocurre en el pacto autobiográfico, el yo que postula el pacto testimonial, al menos en su fase inicial, requiere un nosotros al que pertenece y un compromiso político.

A pesar de la validez del género del testimonio, muchos son los críticos que han señalado sus límites y aporías. En un artículo del 2004, Reati observa que, por su índole fuertemente política y su carácter autojustificatorio, aquellos primeros testimonios carcelarios argentinos de los 80 a veces impidieron el procesamiento social del trauma y fueron, por tanto, menos efectivos que algunas novelas que convirtieron la dolorosa experiencia de la dictadura en ficción. En las narrativas de los hijos se adopta una actitud aún más crítica frente a esas taras del testimonio, que se hace visible a través de ciertas modalidades de distanciamiento como el humor, el rechazo de dimensiones consideradas inherentes al género como la victimización de su narrador, la omnipresencia del aspecto comunitario y de las consignas ideológicas, o la incorporación de un fuerte componente ficcional, reñido con el pacto de lectura testimonial en dos

\footnotetext{
6 Aunque dos de los relatos encajan mejor en la modalidad "fantástica" de la autoficción de Colonna, la variante resulta más cercana al pacto novelesco, en la que un escritor, como héroe de la historia, transforma su existencia real en inverosimilitud biográfica, pero conservando la marca identitaria del nombre propio.
} 
aspectos: en su paso del énfasis en lo colectivo al énfasis en lo individual, y de un contrato de lectura referencial a otro ambiguo. Por ello, si es verdad que se hace uso del testimonio en la narrativa más reciente sobre la dictadura, se trata de un uso desviado, una especie de manipulación irreverente, de tipo "pos". Por otra parte, puede que, en el fondo, tal desacralización sea menor de lo que aparenta ser. No olvidemos que, a raíz de casos polémicos como el de Rigoberta Menchú, el testimonio empezó a ser enfocado como una construcción, una disposición retórica de los materiales en que se basaba, antes que como una mera transcripción de los hechos. El cuestionamiento de la transparencia del género provocó todo un proceso revisionista de la teoría testimonial de los años 70 y 80, como se desprende de los planteamientos de Yúdice (1992) o Amar Sánchez (1992), lo que causó su desplazamiento hacia nuevos espacios interpretativos. Por su parte, los Trauma Studies (Caruth 1995) demostraron que los acontecimientos límite, por el tremendo impacto que producen sobre la conciencia de los sujetos que los sufren, generan irremediablemente omisiones y tergiversaciones que escapan a la propia voluntad y comprensión del testigo, por lo que estos relatos no pueden ser sino resbaladizos.

La tendencia a aflojar las exigencias de referencialidad, esta transgresión abierta del protocolo del "relato de los hechos", es un rasgo que comparten todos los autores del corpus y que es llamativo, dado que contrasta con el afán de veracidad que caracterizaba a la producción memorialística de la generación anterior, la de los directamente afectados por la dictadura. En cambio, la abierta tendencia (auto)ficticia se manifiesta casi exclusivamente en la obra de escritores que pertenecen a la segunda generación, que sienten la necesidad de dar fe de sus dificultades para asumir una identidad propia y se presentan como sujetos fracturados por los complejos orígenes de su genealogía familiar. Su idiosincrasia se entiende mejor si se la relaciona con las propuestas teóricas acerca de la memoria desarrolladas en los últimos años, muy especialmente con la perspectiva de la posmemoria, tal como ha sido conceptualizada por Marianne Hirsch a partir del Holocausto7. Con este término, Hirsch (2002: 22) ha querido presentar una herramienta heurística que permita ir más allá de conceptos no pensados específicamente para la memoria de un pasado traumático. Designa la transmisión de la memoria de una generación a otra, la presencia de dos niveles distintos de subjetividad, lo que implica simultáneamente una distancia temporal y una conexión personal, afectiva. La posmemoria es, siempre según Hirsch, un tipo especial de memoria al ser indirecta y vicaria, por lo que requiere un trabajo de reconstrucción de sentidos bien particular, diferente del recuerdo vivencial. Como tampoco puede ser mera reconstrucción retórica ni ideológica de clisés de la generación anterior, implica una inversión creativa y significa siempre una relectura imaginativa y un replanteamiento de la historia desde una posición subjetiva: la de los herederos. El corpus sobre cuya base se forja la conceptualización de Hirsch está compuesto por fotografías de familia, pero ilumina el problema de la transmisión más allá de este tipo de materiales.

\footnotetext{
${ }^{7}$ Sin embargo, como la infancia de la generación de hijos transcurrió en una situación específica, el "modelo del Holocausto" que domina en los Memory Studies (y por lo tanto también en Hirsch) sólo es parcialmente aplicable a la situación en el Cono Sur (ver al respecto Ciancio 2003).
} 
En este sentido, podríamos considerar la abierta exhibición del carácter subjetivo y ficticio del testimonio en la narrativa escrita por los hijos como el reconocimiento de su ambigüedad, característica que siempre ha sido intrínseca al género. Siendo así las cosas, hay que darle la razón a la estudiosa argentina Beatriz Sarlo cuando, en su crítica de la noción de Hirsch, que formula en Tiempo pasado (2005), postula una continuidad entre memoria y posmemoria, argumentando que la memoria directa tampoco garantiza ninguna verdad transparente. Aparte de poner en duda la aplicabilidad del concepto de Hirsch a contextos que no sean el Holocausto, Sarlo se burla de la proliferación del prefijo "pos", que considera un síntoma de inflación teórica (2005: 132). Pero, cuando ataca al concepto de posmemoria, lo hace en primer lugar porque lo considera un neologismo innecesario (2005: 128). La autora ve sus supuestas particularidades como atributos no privativos de una generación determinada, la generación siguiente a la que padeció los acontecimientos (2005: 126), ya que considera que toda reconstrucción del pasado es siempre, por definición, vicaria, mediada y fragmentaria (2005: 129-130, 136-138). Aunque la reacción de Sarlo parece excesiva -puesto que la generación de los hijos sin duda sí tiene rasgos evidentes dignos de análisis ante los cuales el prefijo "pos" puede resultar pertinente y conviene, por tanto, contemplar una gradación de lo mediado-, su visión merece ser tenida en cuenta a la hora de evaluar los testimonios escritos durante la dictadura e inmediatamente después. Si, como sostiene la crítica argentina, cualquier representación contiene necesariamente un grado de distanciamiento que implica algún tipo de mediación, la creciente hibridación del testimonio que se observa en los últimos años no constituiría una ruptura, sino la extensión lógica de los fines de esta tradición.

Por otra parte, conviene insistir en el hecho de que la metamorfosis del testimonio no sólo tiene motivos textuales, sino también contextuales. La política a favor de las organizaciones de derechos humanos, puesta en marcha por el gobierno de Néstor Kirchner, ha consagrado al militante-víctima. Por muy legítima que haya sido esta rehabilitación, también ha llevado consigo una serie de efectos perversos, como son la institucionalización de cierto discurso monolítico y esencialista de la identidad (Gatti 2008), una inflación memorialística (según la tesis de Andreas Huyssen 1995), una recuperación política de las víctimas y la "entrada al mercado" del desaparecido. Frente a esta oficialización de la memoria, es lógico que los hijos intenten sacudirse los discursos heredados, buscando adoptar una mirada renovada y experimentando con nuevos modos expresivos para referirse al trauma cultural.

\section{ACENTUACIÓN DEL COMPONENTE FICCIONAL: RELEVANCIA Y FUNCIONALIDAD}

El recurso a elementos autoficcionales en las narrativas del yo publicadas en los últimos años encaja claramente en el fenómeno del "giro subjetivo", diagnosticado, entre otros, por Sarlo en su ya mencionado ensayo de 2005. De acuerdo con su planteamiento, el actual protagonismo de las escrituras de la memoria ha sido provocado por un cambio en el objeto de la historia, que ahora 
se concentra en "los derechos y la verdad de la subjetividad" (Sarlo 2005: 22). Esta reorientación implica que para el estudio de la cultura y la historia se legitima la subjetividad de un discurso y que el yo aparece como eje de la experiencia social. En la literatura, este "giro subjetivo" ha tenido su correlato en un "giro autobiográfico", cuyo eje no sólo es el yo, sino también las reflexiones sobre el discurso en primera persona y la construcción de un lugar de sujeto. Sarlo ha criticado esta restitución de la centralidad de la primera persona que narra su vida en, por ejemplo, el género del testimonio, porque a su modo de ver el yo nunca puede constituir una herramienta fiable de conocimiento (Sarlo 2005: 22). Podría argumentarse que la llegada del "giro autoficcional" constituye un nuevo vuelco en esta problematización del yo. A pesar de que con él se ha exacerbado aún más la fuerte implicación de la subjetividad, también sirve en parte para corregir las asunciones algo ingenuas, presentes en la tradición del testimonio; como ya se ha dicho, la autoficción desconfía de la capacidad referencial del lenguaje y de la fidelidad de la memoria, prefiriendo exhibir sus fisuras.

Resumiendo, resulta que la incorporación de una matriz ficcional permite conseguir básicamente dos objetivos: por un lado, apartarse de un discurso institucionalizado $y$, por tanto, previsible y artísticamente agotado sobre la condición de víctima, y, por el otro, llegar a una mayor autenticidad en la representación de un yo, cuyo vínculo con el pasado pasa forzosamente por la imaginación, ya que ese pasado es, para quienes no lo han vivido, una ficción más.

Exploraré ahora cómo se plasma, en un libro concreto, esta tensión entre la vertiente referencial/testimonial y la vertiente autoficcional, y cuál es la funcionalidad de la mezcla contradictoria de las dos pragmáticas antagónicas.

\section{ANÁLISIS DE "Otras fotos de mamá" (76)}

Conviene mencionar que Félix Bruzzone, nacido en el fatídico año del Golpe, encarna junto a coetáneos suyos como Albertina Carri o Mariana Eva Pérez el grado más puro de la posmemoria, ya que sus padres, integrantes del Ejército Revolucionario del Pueblo, fueron secuestrados y no llegó a conocerlos, siendo su abuela paterna quien se encargó de criarle.

76, el primer libro de Bruzzone, publicado en 2007, es un volumen de cuentos en el que predomina un estilo coloquial y lacónico. Muchos son los elementos textuales y paratextuales que condicionan una lectura autobiográfica-testimonial de los relatos. Para empezar, el título del libro es una referencia explícita a la dictadura, pero también es el año de nacimiento del autor. En el 76 desaparecieron sus dos padres, hecho que se destaca en la contratapa (peritexto) y que condiciona la mirada "desde dentro" que adopta el narrador en cada uno de los relatos, lo que ha sido subrayado también en declaraciones públicas del autor (epitexto). La confirmación de estos datos autobiográficos proviene de elementos externos al texto: en ningún momento se establece una homonimia explícita entre el autor y el narrador, sino que la ratificación de la identidad es tácita, efectuándose a través de un "yo" anónimo que, eso sí, comparte múltiples rasgos biográficos con el autor (su situación familiar, su edad, su medio sociocultural, su profesión...). 
La adscripción genérica del texto es contradictoria: en la contraportada, el volumen se anuncia como triplemente codificado: pretende ser autobiografía, colección de cuentos, pero también novela, en dos de sus variedades: "Autobiografía, libro de cuentos, protonovela o novela rota, 76 se comporta como voz actual, radiante por momentos y desalmada de la pasión libertaria de los 70 . Y de lo que vino después". Todos los relatos giran en torno a la orfandad. Con la excepción de "Susana está en Uruguay", tienen como protagonista y enunciador a un hijo de desaparecidos que se ha armado una familia sustituta, compuesta por una abuela o una tía. La ausencia de los padres constituye el eje central de cada texto y atosiga al personaje principal, volviendo una y otra vez bajo diversas formas. Se condensa, por ejemplo, en ciertos objetos tangibles en los que se encuentran combinadas la vida y la muerte, porque antaño fueron efectos personales de los padres, o en ciertas anécdotas que guardan relación con ellos, pero también va desplazándose en las frecuentes pesadillas del protagonista.

Si los efectos de la dictadura funcionan como elemento aglutinante del libro, esa presencia aparece deliberadamente sesgada. El narrador de 76 no busca ser portavoz de una comunidad, pues admite no sentir afinidad con la lucha revolucionaria y no le interesa militar en una organización como H.I.J.O.S, si bien lo colectivo queda latente en varios de los relatos, pero siempre relegado a un segundo plano. El deseo de narrar surge más bien de una necesidad individual de buscar respuestas a los grandes interrogantes que le persiguen: más que explicarse el enigma de la militancia de sus padres, le importa recomponer el agujero negro de su imagen cotidiana a partir de un registro íntimo y doméstico. Aborda lo público desde lo privado y privilegia el detalle concreto frente a lo general. Merece destacarse el conflicto que, en repetidas ocasiones, genera el doble vínculo frente a la desaparición de los padres. Por una parte, su ausencia funciona para el protagonista como un imán, un deseo obsesivo y nunca realizado de recibir respuestas, a fin de poder completar el rompecabezas de su identidad amputada. Simultáneamente, se observan las ganas del personaje de no ver reducida su identidad a esta condición de "hijo de", de liberarse de ese peso para continuar con su vida.

Contrariamente a lo que pasa en la novela Los topos (2008), del mismo autor, los relatos recogidos en 76 conservan una llamativa orientación realista, aunque en todos ellos, tarde o temprano, termina interviniendo la ficción, que se manifiesta mediante ciertos elementos diegéticos. Todos los relatos contienen claramente aspectos inexistentes o inventados que van desplegándose a través de escenas distorsionadas e hiperbólicas (como la escena de la borrachera, que se cuenta en el desenlace de "Otras fotos de mamá"), ingredientes oníricos o tramas francamente disparatadas, como la invención de cigarrillos que pueden fumarse bajo la lluvia en "Fumar abajo del agua" o la experimentación con la ciencia ficción en "2073". La presencia de tales elementos en los propios cuentos justifica la clasificación "protonovela", propuesta en la contratapa de 76.

El relato "Otras fotos de mamá" (Bruzzone 2007: 37-46) se vertebra en torno al cuestionamiento irónico del discurso testimonial, entendido como fuente indiscutible de verdad. Dirige sus dardos contra la sacralización de dos de sus 
formas de aparición más contundentes: la transmisión oral que tiene lugar en las entrevistas con testigos, que fueron antiguos compañeros de lucha de las víctimas, y los objetos con sentido testimonial, tales como las fotografías familiares o las cartas. En este cuento, el narrador, un joven que busca información sobre su madre desaparecida, logra conectarse con un ex novio de aquella y ex militante del Partido Comunista, llamado Roberto, que le muestra fugazmente dos fotos: "en una están los dos abrazados en la orilla de un canal; en la otra, ella fuma en un balcón y mira hacia abajo" (37). Este joven nunca consigue dialogar con nadie sobre lo que averigua respecto a su madre, pero va apuntándolo en un cuaderno (39). Su desorientación se refleja en el acto de emborracharse después de cada pesquisa infructuosa (21).

De hecho, los testigos a los que va a ver suelen terminar hablando sobre todo de sí mismos. Es lo que también sucede con Roberto: "habló de Roma, de una novia italiana y del hijo que tuvieron juntos [...]. De mamá, en cambio, dijo bastante poco" (37-38). Descalificando en estos términos los testimonios de los compañeros de militancia de sus padres, Bruzzone minimiza la contribución de aquellos sobrevivientes que aportan poco más que la reproducción de los discursos oficiales, al tiempo que rechaza una enunciación que parte "desde ellos" y que deja al protagonista con la amarga sensación de verse dominado por los relatos de terceros que precedieron a su nacimiento. Muestra, asimismo, la distancia insalvable entre quienes conocieron a sus padres y él mismo, una incomunicación que repercute en sus pesadillas recurrentes en las que la distancia le aterroriza más que la proximidad (41).

Como era de esperar, la tarde que pasa en casa de Roberto también defrauda sus expectativas: el antiguo militante le hace algunas promesas vagas y evoca su último encuentro ominoso con la madre del joven, que depara más preguntas que respuestas. Al salir de la casa de Roberto, el joven se siente solo y se le pasan por la cabeza imágenes de exclusión: "los parques llenos de gente, el sol, las sombrillas que tapan el sol y yo que llego cuando ya no hay lugar ni sombrilla y que entonces me tengo que quedar solo a un costado" (39).

Después, tiene la oportunidad de volver a ver a Cecilia, la novia actual de Roberto, y de nuevo espera la revelación de una confesión que tampoco llega esa vez, porque todo queda en un intercambio de banalidades que no redunda en nada concreto: "Por un momento yo había llegado a pensar que ella podría revelarme algo fuerte, algo como que Roberto era mi padre o que él había tenido algo que ver con la muerte de mamá" (43). Por otra parte, resulta paradójico, aunque característico del modo de contar oblicuo de Bruzzone, que el protagonista de "Otras fotos de mamá" evoque con lujo de detalles los encuentros con una pareja que apenas le ayuda a descifrar la nebulosa de la vida de su madre, mientras que deja en la sombra, mencionándolo sólo de paso, como un recuerdo en segundo grado, un testimonio mucho más perturbador, ofrecido por un desconocido que se mantiene en el anonimato, sobre una posible versión de su asesinato a manos de la policía (43).

Con Roberto y Cecilia, a fin de cuentas, hubiera sido preferible el silencio a tanta charla, lo que se confirma en la escena final del cuento. Allí, el protagonista 
da a entender que se siente menos desamparado tomando vino sentado al lado del chino del supermercado local, al que no comprende, que en compañía de esos supuestos informantes con los que, de todas maneras, tampoco ha podido establecer un verdadero contacto. El relato no concluye, pero tiene como todos un final abierto preocupante que subraya la perdurabilidad de los hechos traumáticos: el joven tendrá que armarse una imagen de su madre y construirse un presente sin disponer de los datos tan anhelados.

La carencia, la escasez de los hechos y la ausencia de recuerdos reales configuran el tema clave de "Otras fotos de mamá", como es el caso de muchos cuentos del volumen. No es una casualidad que esta falta de información se plasme en las fotos de la madre del protagonista. Al no disponer de recuerdos personales, los únicos puntos de anclaje del narrador son objetos vinculados con la infancia, que se han convertido en una suerte de talismanes. Son instrumentos de la memoria, objetos puente entre el pasado y el presente, y entre ellos ocupa un lugar privilegiado la foto.

Todos los estudios sobre fotografía, de Barthes a Sontag, recalcan que la foto reviste un estatuto especial, el de un soporte memorialístico que irradia autenticidad. Siendo la prueba incontrovertible de que alguien o algo existió, posee un gran poder de credibilidad por la estrecha relación que mantiene con la realidad. Por su parte, Hirsch (2002) también ha dedicado especial atención a la fotografía de familia, que ella considera el medio por excelencia para conectar la memoria de ambas generaciones y para procesar el trauma. $Y$ en el contexto particular de la última dictadura argentina, la foto ha sido por cierto una de las formas más usadas para corporizar a las víctimas y establecer nexos entre la vida y la muerte. Los retratos que se llevaban en las manifestaciones de familiares de desaparecidos hicieron de la fotografía el emblema por excelencia de organizaciones como Madres y Abuelas de Plaza de Mayo, o H.I.J.O.S. Estos retratos condensaban los rasgos de una identidad, un nombre y un rostro.

El protagonismo que adquieren las fotos para evocar la memoria también es una constante en la producción artística de los hijos, por mucho que el trabajo de estos últimos obedezca a voluntades estéticas diversas. Ya en 2000, Lucila Quieto realizó reencuentros visuales imaginados en sus montajes fotográficos Arqueología de la ausencia, que recrean momentos irreales en los que hijos y padres, separados por la muerte, se yuxtaponen en una misma imagen. En sus respectivos documentales Encontrando a Víctor (2004) y M (2007), tanto Natalia Bruschtein como Nicolás Prividera, en un intento de reconstruir la memoria visual, tomaron prestado este principio de superposición fotográfica para autorretratarse, en una especie de collage, junto a la proyección de una de las fotografías que heredaron de sus padres.

Sin embargo, en 76, las fotos ya no funcionan así, sino que se llenan de opacidad una y otra vez. En "Otras fotos de mamá" el narrador nunca recibirá una copia, nunca las va a poseer, pero tampoco puede dejarlas atrás. Cuando sí aparecen y puede contemplarlas, como en "En una casa en la playa", son borrosas y desfiguradas; tocan lo real sin facilitar el acceso a lo real. En su lectura de 76, Juan Terranova (2010) ha llamado "descentrados" a este tipo de objetos. Por 
la distancia temporal, se convierten cada vez más en la representación de una ausencia que hace falta interpretar y cuyos significados hay que recuperar. Las fotos persisten, pero han perdido nitidez.

Se podría sostener que los retratos de los padres no sólo han perdido su índole epifánica, sino también su potencial de sinécdoque: originalmente, traían consigo, más allá de lo que mostraban, su contexto de producción, el universo de sentidos del que fueron retirados, como una sinécdoque encierra parte del referente para totalizar un sistema de significados y devolver una noción de persona. En "Otras fotos de mamá", las fotos ya no remiten con tanta fuerza a lo colectivo, sino que han ingresado en el círculo de la búsqueda subjetiva. El narrador ya no puede volverse parte del "nosotros" del testigo, del mismo modo en que los propios testigos ya no pueden postular su saber. De ahí que las fotos ya no sirvan para reconstruir el pasado y que la identidad de los retratados resulte deconstruida.

Salvando las diferencias que tienen que ver con las restricciones inherentes al medio literario, este tratamiento de las fotos hace pensar en el llamativo ocultamiento icónico que tiene lugar en la película Los rubios, de Albertina Carri, donde el efecto es aún más poderoso por producirse en un entorno audiovisual. En este documental, el modo en que los retratos de los padres se presentan señala que la cineasta ha renunciado a completar los vacíos de su álbum familiar porque nunca se ven $y$, cuando se evocan, se imposibilita la identificación de quienes posan en ellos. Esta técnica parece indicar que no queda más remedio que asumir su ausencia irreparable.

De la misma manera, las fotos inexactas que aparecen en 76 dan un carácter de irrealidad a lo presentado, llenándose de resonancias narrativas. El narrador se da cuenta de que ya no es posible hacer revivir a su madre por medio de sus imágenes y que la inmediatez referencial debe ser sustituida por otras técnicas anamnésicas. Para poder llenar ese vacío, tampoco puede conectar con el pasado a través de una militancia política que recupere la lucha de sus padres. Cuando piensa encontrar consuelo en los relatos ajenos, pronto descubre que es un engaño, ya que muchas veces prometen poder ofrecer revelaciones que finalmente no llegan o que tienen una fiabilidad dudosa por el modo confuso o sospechoso en que han surgido.

$Y$, sin embargo, es a partir de estos vestigios que tiene que buscarse el salto hacia el futuro, el salto de un pasado fracturado hacia la construcción de una identidad adulta. Si la historia de la madre no está disponible, tiene que ser fabulada a través de las fantasías que desde su infancia ha empezado a elaborar sobre ella y su destino como bálsamo a su pérdida, y que ahora sigue tejiendo desde la densidad textual. La única forma de conectarse de manera auténtica con ese pasado y de instaurar un lazo afectivo es, paradójicamente, por la vía de la imaginación. De la misma manera, las "fotos de mamá" se tiñen irremediablemente de ficción y cobran una potencia narrativa. O sea que la fabulación del yo se vuelve mucho más importante que la verdad referencial, lo que convierte al relato en un texto que posee varios de los rasgos de lo que Gasparini considera una "autonarración", un texto autobiográfico y literario que se caracteriza por su 
"fragmentación, alteridad, heterogeneidad y autocomentario", y cuyo objetivo es "problematizar las relaciones entre la escritura y la experiencia" (Gasparini 2012: 193).

De ahí que el pacto que Bruzzone establece con el lector para transmitir su experiencia no sea al cien por cien autobiográfico, sino que pasa por un conglomerado que incluye la imaginación y la creación artísticas, concebidas no como círculo paralelo a la realidad, sino como vía de acceso privilegiada a ella, dimensión constitutiva de lo real que permite lograr un yo más verdadero.

\section{A MODO DE CONCLUSIÓN}

En otro orden de cosas, es evidente que el auge de las biografías autoficcionales no se emparenta con la redefinición de la intimidad que se ha dado en llamar "extimidad", o sea, la autoexposición del yo, el impulso irrefrenable de exhibir la propia intimidad en el espacio público a través de los medios de comunicación o internet (Facebook, los blogs), como han venido demostrando antropólogos como Sibilia (2008). El proyecto que cuaja en libros como 76 no entronca en primer lugar con el impudor, la vanidad o la autopromoción, sino mucho más con esa urgencia existencial que Gasparini detectó en los relatos autobiográficos de supervivientes del Holocausto: con la necesidad imperiosa de rastrear un trauma familiar para posibilitar un nuevo comienzo.

En el proceso, la verdad irremediablemente perdida de lo evocado es menos importante que lo experimentado cada vez que se evoca. Lo que vuelve finalmente no es un recuerdo, sino una escritura, la posibilidad de transformar la crueldad intolerable de la historia de la madre al insertarla en un relato. Todo este proceso desemboca en la existencia de aquel cuaderno en el que el protagonista de "Otras fotos de mamá" ordena los fragmentos que va recopilando sobre la vida de su progenitora, un cuaderno repleto de vacíos y silencios que actúa como un lugar de remembranza. Es un tipo de escritura que parte de la concepción de la memoria como artificio y que se alimenta de la imaginación no como algo fingido o inventado, sino como un espacio forjado. El foco se halla en el carácter performativo del escribir (como lo entiende Nichols 1991²), en la liberación que el autor experimenta, frente a los límites de la autobiografía, a través de la labor creadora y en el intento de liberar a su madre de la trayectoria que condujo a su tragedia.

Es esta tensión o fricción, esta puesta en crisis de la legibilidad del pasado, la que hace tan productivos los relatos de los hijos que se han publicado en los últimos años. Ofrecen la particularidad de que no denuncian ni reivindican, sino que muestran y cuestionan, moviéndose en los márgenes de diferentes ejes genéricos como el del testimonio canónico o el de la novela autobiográfica clásica, sin estar por eso atados a las normas clásicas que determinan aquéllos. El narrador de 76 es un yo discontinuo que interrelaciona inextricablemente estra-

8 Nichols ha llamado "performativos" a los documentales narrados en primera persona que se caracterizan por un tratamiento esencialmente subjetivo. El autor es también personaje de su propia obra, lo que provoca una aproximación afectiva entre él y el objeto de su obra. 
tegias autobiográficas y autoficcionales para comprenderse mejor. Se le aplica una formulación que ha propuesto Vincent Colonna, sin darse cuenta de que en ciertos contextos, como el argentino de la posdictadura, iba a ser necesario tomársela muy al pie de la letra: "Comme l'autobiographie, l'autofiction est pour l'auteur une manière d'explorer les mystères de son nom propre" (1989: 53).

\section{OBRAS CITADAS}

Alberca, Manuel (2007): El pacto ambiguo. De la novela autobiográfica a la autoficción. Madrid, Biblioteca Nueva.

Amar Sánchez, Ana María (1992): El relato de los hechos. Rodolfo Walsh: testimonio y escritura. Rosario, Beatriz Viterbo Editora.

Avelar, Idelber (2000): Alegorías de la derrota: la ficción postdictatorial y el trabajo del duelo. Santiago, Cuarto Propio.

Beverley, John (1987): "Anatomía del testimonio", Revista de Crítica Literaria Latinoamericana, n. 25 , pp. $7-16$.

Bruzzone, Félix (2007): 76. Buenos Aires, Tamarisco.

- (2008): Los topos. Buenos Aires, Mondadori.

Caruth, Cathy (ed.) (1995): Trauma. Explorations in Memory. Baltimore/Londres, John Hopkins University Press.

Casas, Ana (ed.) (2012): La autoficción. Reflexiones teóricas. Madrid, Arco Libros.

Ciancio, María Belén (2013): "Sobre el concepto de postmemoria". Disponible en <http://www.proyectos.cchs.csic.es/fdh/sites/default/files/2-2\%20Ciancio.pdf>. Última visita: 20.03.2014.

Colonna, Vincent (1989): L'autofiction: essai sur la fictionnalisation de soi en littérature. Disponible en <http://tel.archives-ouvertes.fr/docs/00/04/70/04/PDF/tel-00006609. pdf $>$. Última visita: 25.09.2013.

_ (2012): "Cuatro propuestas y tres deserciones (tipologías de la autoficción)" [2004]. En: Ana Casas (ed.), cit., pp. 85-123.

Drucaroff, Elsa (2011): Los prisioneros de la torre. Política, relato y jóvenes en la postdictadura. Buenos Aires, Planeta.

Garibotto, Verónica (2008): Contornos en negativo: reescrituras postdictatoriales del siglo XIX (Argentina, Chile y Uruguay). University of Pittsburgh (tesis doctoral). Disponible en <http://core.kmi.open.ac.uk/download/pdf/12206943.pdf>. Última visita: 21.10.2014.

Gasparini, Philippe (2012): "La autonarración" [2008]. En: Ana Casas (ed.), cit., pp. 177-211.

Gatti, Gabriel (2008): El detenido-desaparecido: narrativas posibles para una catástrofe de la identidad. Montevideo, Trilce.

Hirsch, Marianne (2002): "Mourning and Postmemory" [1997]. En: Family Frames. Photography, Narrative and Postmemory. Cambridge (Massachusetts), Harvard University Press, pp. 17-41.

Huyssen, Andreas (1995): Twilight Memories. Marking Time in a Culture of Amnesia. Nueva York, Routledge. 
Journal of Romance Studies, vol. 13 n.³, 2013. Monográfico Revisiting Postmemory: The Intergenerational Transmission of Trauma in Post-Dictatorship Latin American Culture.

Lejeune, Philippe (1975): Le pacte autobiographique. París, Seuil.

Nichols, Bill (1991): Representing Reality. Issues and Concepts in Documentary. Indiana, Indiana University Press.

Partnoy, Alicia (1986): The Little School: Tales of Disappearance and Survival in Argentina. Pittsburgh, Cleis.

Reati, Fernando (2004): "Duelo, trauma y derrota en las novelas de ex presos de la Guerra Sucia argentina", Chasqui, vol. 33, n. ${ }^{\circ}$ 1, pp. 106-127.

Ros, Ana (2012): The Post-Dictatorship Generation in Argentina, Chile, and Uruguay. Collective Memory and Culture Production. Nueva York, Palgrave Macmillan.

Sarlo, Beatriz (2005): Tiempo pasado. Cultura de la memoria y giro subjetivo. Una discusión. Buenos Aires, Siglo Veintiuno.

Sibilia, Paula (2008): La intimidad como espectáculo. Buenos Aires, Fondo de Cultura Económica.

Terranova, Juan (2010): "Sobre 76 de Félix Bruzzone", Eterna Cadencia, 13 de mayo. Disponible en <http://blog.eternacadencia.com.ar/archives/2010/7820>. Última visita: 13.09 .2013$.

Timerman, Jacobo (1982): Presa sin nombre, celda sin número. Buenos Aires, El Cid Editor.

Yúdice, George (1992):"Testimonio y concientización", Revista de Crítica Literaria Latinoamericana, n. ${ }^{\circ} 36$, pp. 207-227. 